\title{
Shape dynamics of silica scales (Chrysophyceae, Stramenopiles) associated with pH
}

\author{
Yvonne NĚMCovÁ* \& Martina PichrTovÁ
}

Department of Botany, Charles University in Prague, Benatska 2, Praha 2, 12801 Czech Republic; *Corresponding authore-mail: ynemcova@natur.cuni.cz

\begin{abstract}
We investigated the shape dynamics of silica scales in relation to environmental $\mathrm{pH}$ in two freshwater algal flagellates, Mallomonas striata and Synura echinulata, using landmark-based methods of geometric morphometrics. $\mathrm{pH}$ has been implicated as a primary factor controlling the occurrence and distribution of these protists. Moreover, scales are preserved in sediments and provide important proxy data of past and recent environmental changes. We concluded that the $\mathrm{pH}$ of the cultivation medium significantly affected scale biogenesis and influenced the final shape of produced silica scales. In addition, we asked how size of the scales was related to their shape (allometric effect). Scales produced under various levels of $\mathrm{pH}$ treatment were significantly different in shape in both investigated species, even though we eliminated the effect of size. We also investigated phenotypic plasticity (defined as the extent of scale shape variation) within the investigated $\mathrm{pH}$ treatments. Increased phenotypic plasticity is generally accepted to be induced by environmental stress. The impact of $\mathrm{pH}$ on $M$. striata and $S$. echinulata population growth was used to evaluate optimal/suboptimal conditions. We revealed increased scale shape plasticity in either suboptimal conditions (both species) or in high level $\mathrm{pH}$ treatments ( $\mathrm{pH} 8.2$ and 8.7, in $M$. striata). The inability of cells to compose a perfectly fitting, functional scale case, when the shape of individual scales varied considerably, may cause absence of Synurales in highly alkaline natural environments.
\end{abstract}

Key words: Shape dynamics, Geometric morphometrics, pH response, silica scales, Synurophyceae, Chrysophyceae, Synurales, phenotypic plasticity

\section{Introduction}

Synurales represent free living or colonial flagellates residing exclusively in fresh waters. In the multigene molecular phylogenetic analyses Synurales ale included in Chrysophyceae/ Synurophyceae clade(e.g. Grant et al. 2009). Their cells are covered with an armor of imbricated silica scales attached to the plasma membrane. The scale cases are comprised of highly organized, flexible coats, the morphology of which is predetermined and controlled by the cell (LEADBEATER \& BARKER 1995). In Mallomonas some or all scales may harbor a bristle. Silica structures (scales and bristles) are produced endogenously in a silicon deposition vesicle. Taxonomy within this group is still based almost exclusively on species-specific scales identified under the electron microscope. Scales are preserved in sediments for an extended period of time (tens to hundreds of years) depending on environmental conditions. However, the oldest preserved scales were reported from
Middle Eocene (ca. 47 million years old, SIVER \& WOLFE 2005). Silica scales may provide important proxy data of past environmental change (e.g. eutrofication, acidification or shifts of climate; reviewed in Zeeb \& Smol 2001). Many well defined species have a definitive distribution along a $\mathrm{pH}$ gradient, and variations in the species composition are useful biological indicators of pH changes (Siver 1991; Siver 1995). Moreover, $\mathrm{pH}$ is implicated as a primary factor controlling occurrence and distribution of these protists. In natural waters, $\mathrm{pH}$ is regulated by carbonate equilibrium and it is influenced by a combination of geochemical and biological processes. Humic acids also act as a pH buffer, especially at lower pH in humic stained systems (GoNDAR et al. 2005). Water in rivers and lakes show regional differences in $\mathrm{pH}$ depending on the geology and hydrology of the catchment area, input of acidifying substances and productivity of the system. Seasonal/diurnal $\mathrm{pH}$ fluctuation within a given water body is typically less or equal to $1 \mathrm{pH}$ unit (BRÖNMARK \& 
HANSSON 2005).

Synurales are largely confined to neutral and/or slightly acidic waters (SIVER 1995). However, several species have been reported from alkaline habitats, e.g. Mallomonas tonsurata Teiling emend. W. Krieger, M. crassisquama Fott or M. alpina Pascher \& Ruttner emend. Asmund \& Kristiansen (Kristiansen 1985; Siver 1991). The growth restriction at high $\mathrm{pH}$ in Synura petersenii Korshikov was shown to be due to the inability to use bicarbonate as a source of inorganic carbon (SAXBY-Rouen et al. 1997). Bhatti \& Colman (2008) concluded that freshwater Synurales rely on the diffusive uptake of $\mathrm{CO}_{2}$, maintaining a high internal $\mathrm{pH}$ relative to the $\mathrm{pH}$ of the external environment.

Growth responses of Synurales exposed to a gradient of experimental conditions (e.g. $\mathrm{pH}$, temperature, light intensity) were found to be species-specific (LEE et al. 2007), or even strainspecific (WEE et al. 1991). As the silica scales represent important microfossils, the question arose: How is the scale biogenesis influenced by environmental conditions, and is this impact reflected in the scales' morphology? Pioneer works on scale phenotypic plasticity related to temperature were published by GuTOWSKI (1996) and Martin-WagenmanN \& Gutowski (1995). They found that higher cultivation temperature caused a shortening of scales and bristles. The effect of $\mathrm{pH}$ on scale morphology was investigated by Gavrilova et al. (2005), who documented the strain-specific response to suboptimal $\mathrm{pH}$ conditions in Synura petersenii Korshikov. While in the strain CCAP 960/1c scale size was reduced at sub-optimally low $\mathrm{pH}$ and not affected at high $\mathrm{pH}$, the response of strain CCAP $960 / 3 \mathrm{c}$ was the opposite.

We expanded upon previous research of $\mathrm{pH}-$ related scale shape plasticity by implementation of an intriguingly efficient tool - landmark based methods of geometric morphometrics (GM). Shape in GM is formalized using digitalized coordinates of biologically definable homologous points - landmarks (BoOKSTEIN 1991). Relative position of landmarks among various objects may be used for multivariate analysis of shape. Extent of plasticity (the variety of shapes) may be quantified using a morphological disparity measure (ZeLDITCH et al. 2004). In silica scaled chrysophyte research, landmark based GM methods have been successfully implemented to investigate temperature induced morphological variation of scales in clonal populations of Mallomonas kalinae Řezáčová, Synura curtispina (Petersen J.B. \& Petersen J.B.) Asmund ( et al. 2010), M. tonsurata Teiling emend. Willi Krieger and S. petersenii (PiChrTové \& NĚMCOVÁ 2011), to characterize the patterns of scale shape variation in S. echinulata Korshikov in combined gradients of light and temperature (NĚMCOVÁ et al. 2010), to describe scale shape variation in relation to their position within the scale-case (Neustupa et al. 2010), and to emphasize the shape differences between scales belonging to the two distinct varieties - Mallomonas striata var. striata Asmund and M. striata var. serrata Harris K. \& Bradley D.E. (NeuSTUPA \& NĚMCOVÁ 2007).

In the present study we describe the effect of $\mathrm{pH}$ on shape of silica scales in two flagellates Mallomonas striata and Synura echinulata. We have primarily concentrated on scale shape plasticity across the entire range of viable $\mathrm{pH}$. In addition, we asked how size of scales may influence their shape (allometric effect).

\section{Materials and methods}

The 2059 strain of Mallomonas striata var. serrata (referred to as M. striata) used in this study was obtained from the Provasoli-Guillard National Center for Culture of Marine Phytoplankton(CCMP); the strain of Synura echinulata (CAUP B702) was originally isolated from a peat bog pool in the National Nature Monument Swamp (Czech Republic) in May 2008.

The experimental cultures were selected from exponentially growing clones and inoculated into 50 $\mathrm{ml}$ Erlenmeyer flasks with buffered fresh medium at an initial cell density 300 cells $\mathrm{ml}^{-1}$. Derived sub clones were grown at different $\mathrm{pH}$ levels. Experiments were carried out in triplicate. The tested $\mathrm{pH}$ range was from 3.5 to 8.7. Fresh DY V medium (https://ccmp.bigelow. org/node/73) was buffered with $1 \mathrm{mM}$ MES $(2-[\mathrm{N}-$ morpholino] ethanesulphonic acid) to $\mathrm{pH} 4.5,5.5$, or 6.5, and with $1 \mathrm{mM}$ HEPES (N-[2-hydroxyethyl] piperazine- $\mathrm{N}^{\prime}-2-$-ethanesulfonic acid) hemisodium salt to $\mathrm{pH} 7.5,8.3$ or 8.7 . Strains were cultivated at an optimum growth temperature of $22{ }^{\circ} \mathrm{C}$ (M. striata) and $17{ }^{\circ} \mathrm{C}$ (S. echinulata) under continuous white fluorescent illumination of $20 \mu \mathrm{mol} \mathrm{m}^{-2} \mathrm{~s}^{-1}$ for 14 to 40 days until stationary phase was observed. The duration of the experiments differed to allow a sufficient number of new scales to be formed under the test conditions. Cell growth was measured at intervals of 2-3 days (later 5-7 days) by absorbance at $750 \mathrm{~nm}$ (Spekol 11, Analytik Jena), and recalculated to cell density. The $\mathrm{pH}$ was checked and adjusted with $\mathrm{NaOH}$ or $\mathrm{HCl}$ every three days (InoLab pH/conductometer 720, WTW). 
During the exponential growth phase, $10 \mathrm{ml}$ of algal suspension from every target $\mathrm{pH}$ was pooled and fixed with Lugol's solution.

For scanning electron microscopy (SEM) acetone-washed glass coverslips were coated three times with a poly-L-lysine solution (1:10 in deionized water) to ensure appropriate adhesion of the cells. Then, a drop of the glutaraldehyde-fixed cell suspension was placed on the glass, transferred into $30 \%$ acetone, and dehydrated by an acetone series. Subsequently, cells were dried to a critical-point with liquid $\mathrm{CO}_{2}$. The glass coverslips were mounted onto an SEM stub with double-sided adhesive carbon tape, coated with gold for $5 \mathrm{~min}$ (3 nm layer) with a Bal-Tec SCD 050 sputter coater and observed with a JEOL 6380 LV scanning electron microscope. Samples for transmission electron microscopy (TEM) were oxidized in peroxide and potassium dichromate to disintegrate the scale case, washed carefully, transferred to grids, and examined with a JEOL 1010 electron microscope. For each $\mathrm{pH}$ level, 70 body scales were chosen and photographed. The experimental organism $M$. striata possesses relatively uniform spirally arranged scales (Fig.1). All scales are provided with a dome, where a slightly curved serrated bristle is attached (Fig. 3). Slightly curved scales from the most anterior ring of scales (surrounding the flagella pore) were excluded from the analyses. Colonies of Synura echinulata typically consist of 1025 cells. The scale case of a single pear shaped cell is composed of several morphological types of scales (Fig. 2). Body scales, caudal and rearmost (slipperlike) scales are arranged from the anterior to posterior of the cell. Scales positioned on the anterior of the cell have the longest spines, and length of the spine decreases as scales are traced from the anterior to the posterior of the cell (SIVER 1999). We used the length of the spine to distinguish the scales of transitional morphology between caudal and body scales. All scales with a spine shorter than $0.9 \mu \mathrm{m}$ were excluded from analyses. Moreover, relatively large scale sets were investigated to minimize the effect of shape variation related to scale position on the cell surface. Length and width of scales was measured in the tpsDig program (RoHLF 2006). To identify significant pair wise differences in length measurements among individual $\mathrm{pH}$ treatments a T-test was used (PAST, ver. 1.81; HAMmER et al. 2001). Results were considered significant if $\mathrm{p}<$ 0.05. Twenty-nine landmarks (LM) were defined on each scale of $M$. striata (Fig. 5) using the TpsDig program. Twelve landmarks were allowed to slide along the outline of the scale (so called semilandmarks). Thirty-two landmarks, including twenty-five semilandmarks were depicted on Synura echinulata scales (Fig. 6). The silica scales represent flat, bilateral, symmetrical or almost symmetrical objects. The side of the scale adjacent to the plasma membrane is smooth, while the other side is structured. Nevertheless, we were not able to discern the left and right sides of an S. echinulata scale on TEM images, so we symmetrized the landmarks in mirror positions, as recommended by KLINGENBERG et al. 2002. Original and mirrored landmark configurations were averaged and superimposed by Generalized Procrustes analysisGPA (Bookstein 1991) in tpsRelw (RohlF 2006). There is, however, a protrusion on an apical portion of the scale (dome) which enables one to distinguish the sides (Fig. 3, arrowhead) in M. striata scales. Original LM coordinates were subjected to GPA.

The principal component analyses (PCA) of the shape data was conducted on all silica scales across a $\mathrm{pH}$ gradient (overall shape variation). Scores for the objects on the first 15 PC axes (spanning 95.4\% of the total variation for Mallomonas striata and $98.2 \%$ of the total variation for Synura echinulata) were used for canonical variates analyses (CVA) in PAST. To test for scale shape differences between individual groups, the scores on the first 15 PC axes were used for two-group multivariate permutation tests (2000 permutations) on the Mahalanobis distance between all group pairs. Shape configurations typical for individual $\mathrm{pH}$ treatments were visualized as thin-plate splines of average group shapes from overall consensus configurations. The multivariate regression of shape data (the Procrustes coordinates) on $\mathrm{pH}$ was performed in tpsRegr (RoHLF 2006). In addition, the multivariate regression of shape data on centroid size was designed to test for the effect of size on shape (allometric effect). The centroid size (square root of the sum of squared distances from the landmarks to their centroid) of each configuration prior to superimposition was used as a size variable. To examine the relation of scale shape on $\mathrm{pH}$, with size-effect controlled for, residuals from this regression ( $\mathrm{R}-2$.6.2, $\mathrm{R}$ Development Core Team 2008) were regressed on $\mathrm{pH}$ (DeBAT et al. 2003). The permutation test (1000 permutations) on Wilk's $\lambda$ and Goodall's F-ratio was used to evaluate significance of all regression models.

To quantify the differences in the extent of scale plasticity among individual $\mathrm{pH}$ treatments the values on partial morphological disparities (measured by a variance) were used (BALTANÁs et al. 2002, Foote 1993, Zelditch et al. 2004). The significance of differences among individual $\mathrm{pH}$ treatments was evaluated by a permutation test with 10 000 permutations using partial morphological disparity as a computed value in $\mathrm{R}-2.6 .2$. routine. 

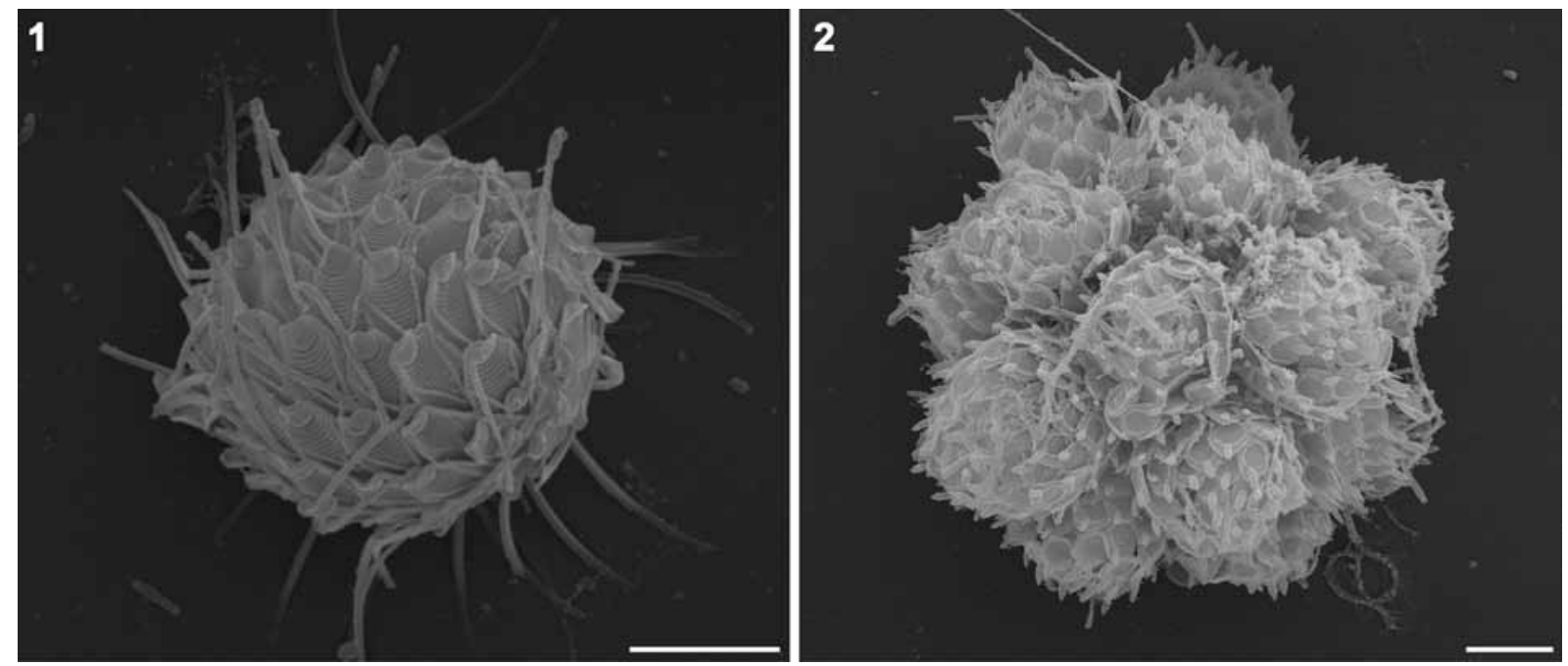

Figs 1-2. Scanning electron micrographs of the investigated strains: (1) Mallomonas striata, scale bar $5 \mu$ m; (2) Synura echinulata, scale bar $10 \mu \mathrm{m}$.

3

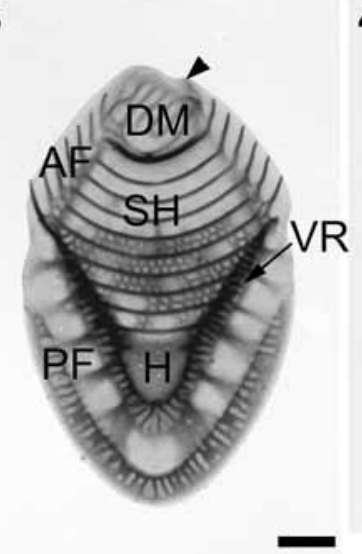

4

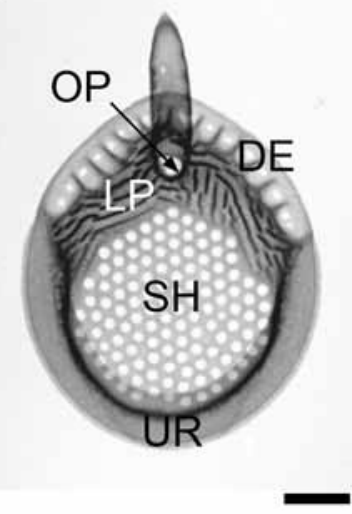

5

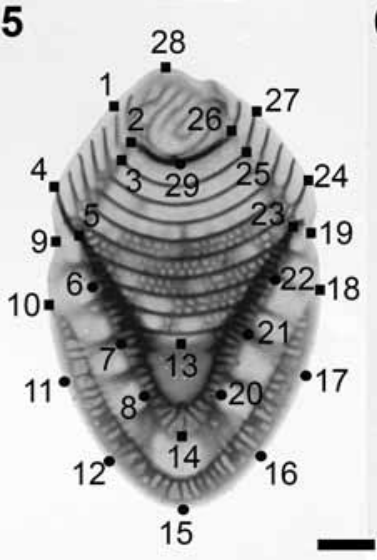

6

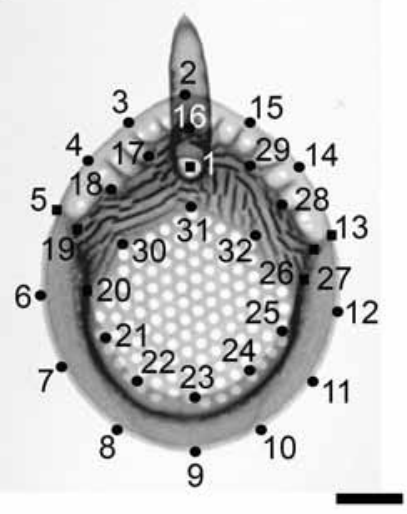

Figs 3-6. Morphological description of scales and the position of landmarks: (3) Mallomonas striata, scale morphology [(AF) anterior flange, (DM) dome, $(\mathrm{H})$ hood, (PF) posterior flange, (SH) shield, (VR) V-rib, (arrowhead) protrusion on an apical part of the scale enables to distinguish the left and right sides]; (4) Synura echinulata, scale morphology [(DE) distal edge with short ribs separated by a single pore, (LP) labyrinthic pattern, (OP) spine opening, (SH) shield, (UR) upturned rim]; (5-6) position of landmarks (squares) and semilandmarks (circles), (5) M. striata, (6) S. echinulata. Scale bar $0.5 \mu \mathrm{m}$.

\section{Results}

\section{Mallomonas striata}

Mallomonas striata exhibited a growth response at a wide $\mathrm{pH}$ range $(4.5-8.7 \mathrm{pH})$. M. striata showed rapid population growth at all investigated $\mathrm{pH}$ levels except pH 4.5 (Fig. 7). No apparent pH effect on M. striata scale size could be concluded. Scale size (expressed as centroid size) was only weakly, however significantly $(\mathrm{r}=0.16$; permutation $\mathrm{p}=$ $0.007)$ positively correlated to $\mathrm{pH}$ (not shown). The scale size measurements were significantly correlated (CS vs. length of the scale $r=0.93$; CS vs. width of the scale $r=0.81$ and length vs. width of the scale $\mathrm{r}=0.62$; all permutation $\mathrm{p}<0.0001$ ).
Further shape-to-size analyses were conducted using CS as a size measure in both investigated species.

The shape of the scales was significantly related to $\mathrm{pH}$ (Wilk's $\lambda=0.294$, permutation $\mathrm{p}$ $=0.001$; Goodall' $\mathrm{F}$-ratio $=160.5$, permutation $p=0.001 ; 27.6 \%$ of variance explained by the regression model). The CVA revealed statistically significant scale shape differences among individual $\mathrm{pH}$ treatments (Wilk's $\lambda=0.057$, $\mathrm{p}<<0.0001)$. All pair wise comparisons on Mahalanobis distance were significantly different (all permutation $\mathrm{p}<0.007$ ). In an ordination space of the first two $\mathrm{CV}$ axes high $\mathrm{pH}$ groups (pH 8.3 and 8.7) clustered together and were 

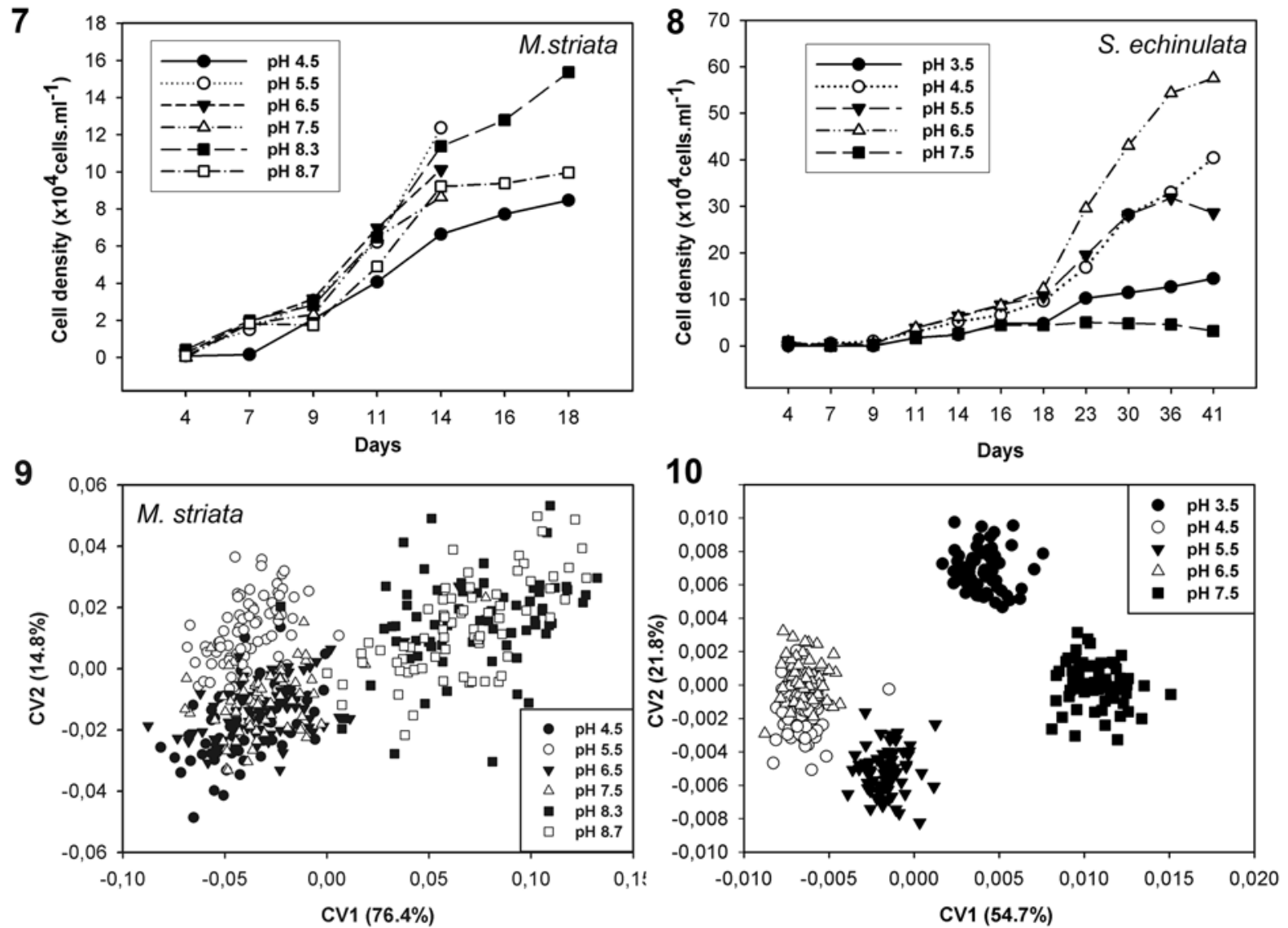

Figs 7-10. (7-8) the growth response curves expressed as cell density vs. cultivation period, (7) Mallomonas striata, (8) Synura echinulata; (9-10) discrimination of shapes from individual $\mathrm{pH}$ treatments. Canonical variate analysis ordination diagram shows individual scale scores along first two canonical axes. Values in brackets indicate the proportion of total variation described along each axis, (9) Mallomonas striata, (10) Synura echinulata.

distinctly separated from the remaining groups (Fig. 9). Mean scale-shapes for each $\mathrm{pH}$ treatment were demonstrated by thin-plate splines (Fig. 11). Silica scales produced under low, neutral and slightly alkalic $\mathrm{pH}$ treatments tended to be wider, with a pronounced V-rib. Scales from treatments at higher $\mathrm{pH}(\mathrm{pH} 8.3$ and 8.7) were thinner and their $\mathrm{V}$-rib was reduced considerably. The multivariate regression of Procrustes coordinates on centroid size confirmed the occurrence of a weak, albeit significant, allometric effect on scale shape accounting for only $2.3 \%$ of the total shape variance (Wilk's $\lambda$ $=0.216$, permutation $\mathrm{p}=0.001$; Goodall' $\mathrm{F}-$ ratio $=9.8$, permutation $\mathrm{p}=0.001)$. The scale shape variations along the size gradient (Fig. 13) were minimal. The smallest scales typically had a slightly reduced shield, short pronounced anterior flanges, and expanded posterior flanges, while the largest scales were characterized by an extensive shield and slightly reduced posterior flanges. The relation of scale shape to $\mathrm{pH}$, with size effect controlled for, remained significant (Wilk's $\lambda=0.335$, permutation $\mathrm{p}=0.001$; Goodall' F-ratio $=99.8$, permutation $\mathrm{p}=0.001 ; 19.1 \%$ of variance explained by the regression model). All pair wise comparisons on Mahalanobis distance remained significantly different (all permutation $\mathrm{p}<0.002$ ). Mean scale-shapes, with the effect of size eliminated (not shown), were very similar to those in Fig. 11.

The values on partial morphological disparity for each of the $\mathrm{pH}$ treatments were used to quantify the extent of scale plasticity. The scales produced under higher $\mathrm{pH}$ (8.3 and 8.7 ) in Mallomonas striata were significantly more morphologically diverse $\left(2.06 \times 10^{-3}\right.$ and $1.79 \times 10^{-3}$ ) compared to all the other groups, although slightly increased plasticity at $\mathrm{pH} 4$ was also observed $\left(1.08 \times 10^{-3}\right)$. Moreover, the differences between adjacent pairs in the $7.5 \mathrm{pH}$ and lower groups were not statistically significant (permutation $\mathrm{p}=0.1029$ to 0.1672 ; Fig. 15). 


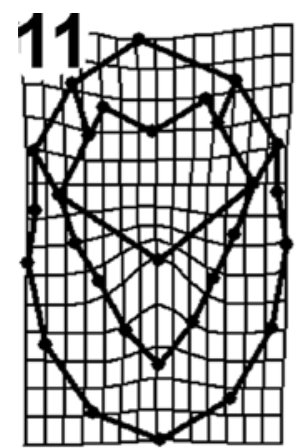

pH 4.5

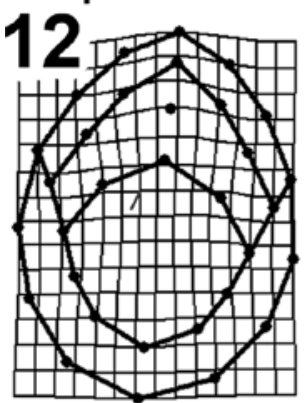

pH 3.5

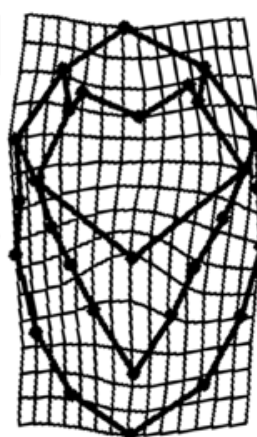

pH 5.5

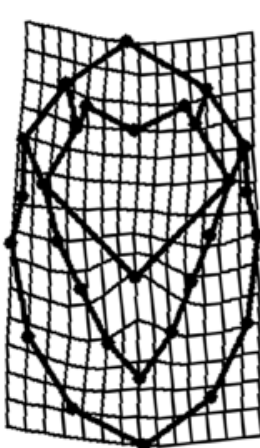

pH 6.5

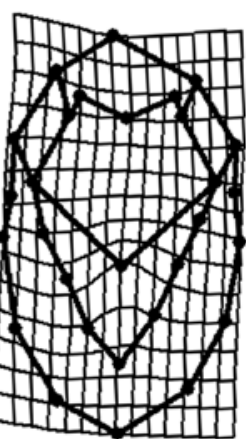

pH 7.5

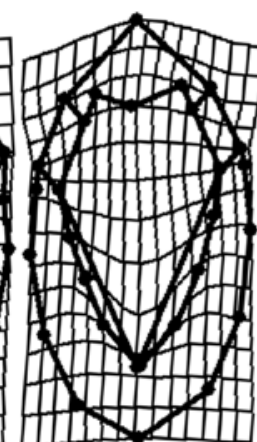

pH 8.3

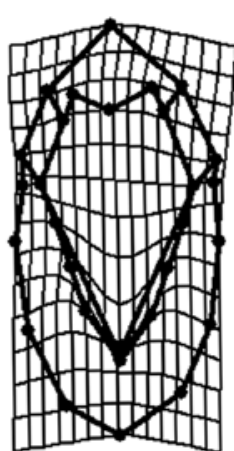

pH 8.7

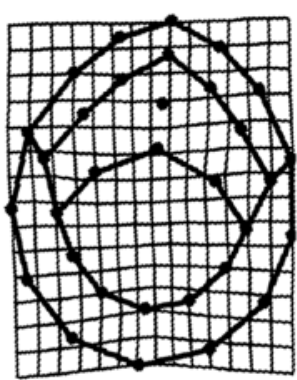

pH 4.5

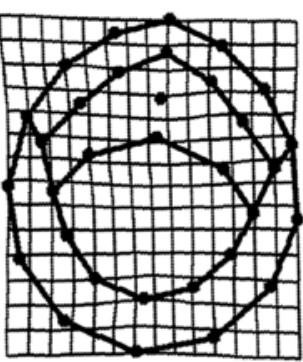

pH 5.5

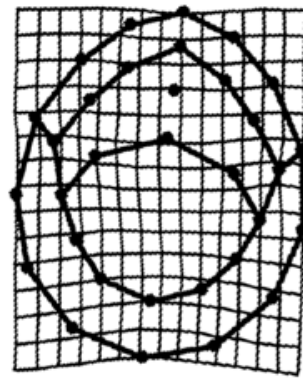

pH 6.5

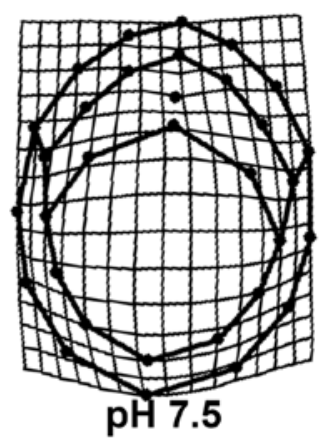

Figs 11-12. Mean shape configurations of individual $\mathrm{pH}$ treatments illustrated by thin-plate splines. Comparisons are expressed as the deformation of the landmarks of overall consensus configuration into those of mean shapes determined for each $\mathrm{pH}$. Scale factor: two times exaggerated to emphasize differences, (11) Mallomonas striata, (12) Synura echinulata.

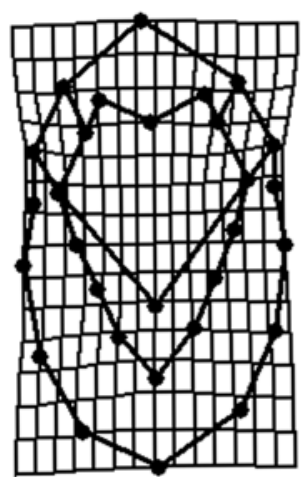

CS - min.

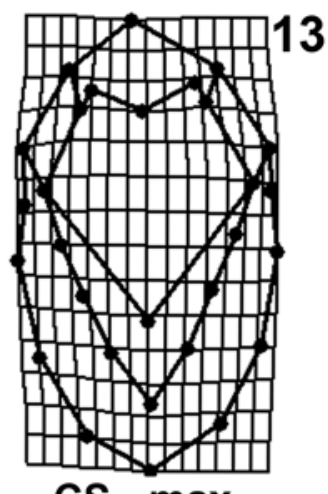

CS - max.

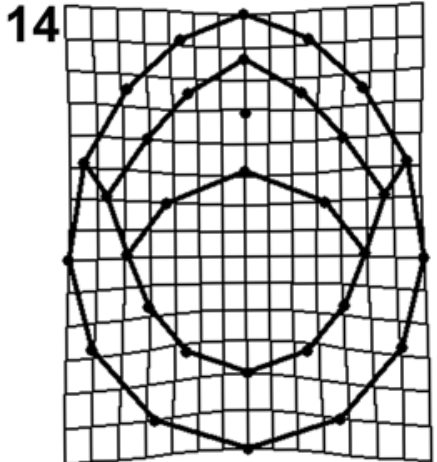

CS - min.

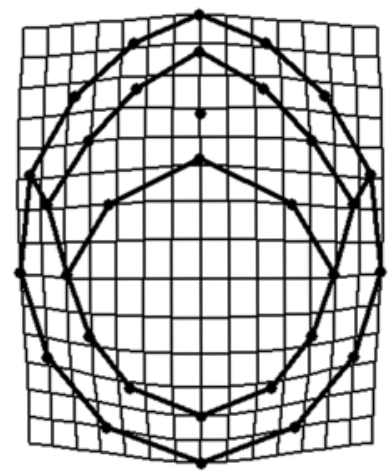

CS - max.

Figs 13-14. Shape configurations reconstructed by the regression model of shape variables on size. Deformations associated with minimum (CS - min.) and maximum (CS - max.) size of the scale are shown, (13) Mallomonas striata, (14) Synura echinulata.

\section{Synura echinulata}

Synura echinulata exhibited a growth response at a $\mathrm{pH}$ range of $3.5-7.5$ (Fig. 8). S. echinulata growth was reduced in $\mathrm{pH}$ treatments $(3.5$ and 7.5 $\mathrm{pH})$. The effect of $\mathrm{pH}$ on $\mathrm{S}$. echinulata centroid size was very similar to that described for Mallomonas striata. The positive correlation was rather weak, however significant $(\mathrm{r}=0.13$; permutation $\mathrm{p}=$ 0.0142 ). Scale size measurements were highly correlated (CS vs. length of the scale $r=0.84$; CS vs. width of the scale $r=0.73$ and length vs. width of the scale $\mathrm{r}=0.48$; all permutation $\mathrm{p}<0.0001$ ).

The scale shape of Synura echinulata was significantly influenced by $\mathrm{pH}$ (Wilk's $\lambda=0.013$, permutation $\mathrm{p}=0.001$; Goodall' $\mathrm{F}-$ ratio $=30.0$, permutation $\mathrm{p}=0.001 ; 8.0 \%$ of variance explained by the regression model). On a CVA scatter plot the scales from an individual $\mathrm{pH}$ treatment formed distinctive clusters. All pair wise comparisons on Mahalanobis distance were significantly different (all permutation $\mathrm{p}<0.0005$ ). The first $\mathrm{CV}$ axis separated the groups of scales produced at $\mathrm{pH}$ 

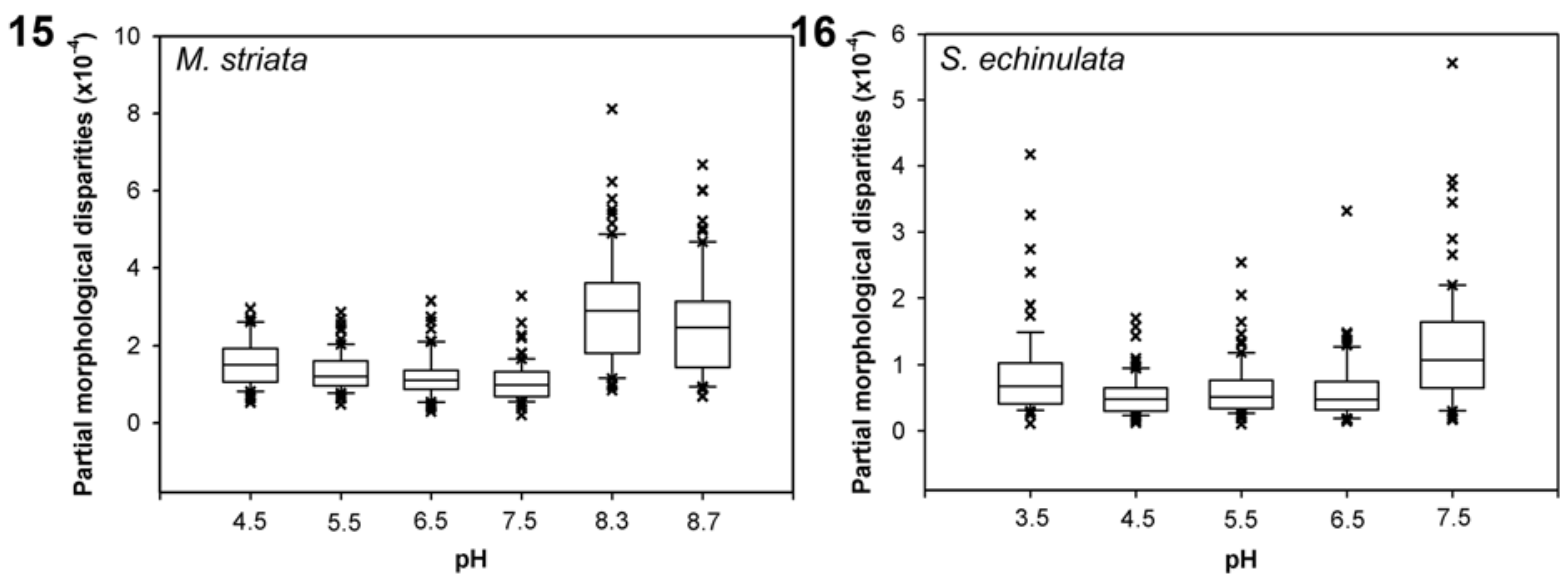

Figs 15-16. Quantitative extent of scale shape plasticity expressed as partial morphological disparity in individual $\mathrm{pH}$ treatments. ×: outlying values, (15) M. striata, (16) S. echinulata.

3.5 and 7.5 from the rest (Fig. 10). The shapes of mean configurations are illustrated by thin-plate splines (Fig. 12). The low pH group (3.5) was characterized by oval scales with reduced shield and expanded secondary labyrinthic pattern area. The scales from $4.5,5.5$ and $6.5 \mathrm{pH}$ appeared to be relatively uniform in shape, and their outline became rounder with increasing $\mathrm{pH}$. The high $\mathrm{pH}$ group (7.5) was distinguished by wider scales with an expanded shield, reduced labyrinthic pattern area and considerably reduced rim. The effect of scale size on shape variables (allometric effect) in Synura echinulata was more apparent then in Mallomonas striata (Wilk's $\lambda=0.575$, permutation $\mathrm{p}=0.001$; Goodall' $\mathrm{F}$-ratio $=22.7$, permutation $\mathrm{p}=0.001 ; 6.2 \%$ of variance explained by the regression model). The shape models reconstructed by multivariate regression revealed similarity between the high $\mathrm{pH}$ group (7.5) scales and the largest scales (Fig. 14). Multivariate regression of the shape component on $\mathrm{pH}$, with size effect controlled for, confirmed a significant relation (Wilk's $\lambda=0.03$, permutation $\mathrm{p}=0.001$; Goodall' $\mathrm{F}$-ratio $=26.6$, permutation $\mathrm{p}=0.001 ; 7.1 \%$ of variance explained by the regression model). All pair wise comparisons on Mahalanobis distance were significantly different (all permutation $\mathrm{p}<0.0005$ ). Mean scale-shapes, with the effect of size eliminated (not shown), were very similar to those in Fig. 12.

Synura echinulata scales exhibited the highest plasticity in marginal $\mathrm{pH} 3.5$ and 7.5 $\left(5.79 \times 10^{-4}\right.$ and $\left.8.95 \times 10^{-4}\right)$, where the growth of cells was restricted (Fig.16). Differences among the other $\mathrm{pH}$ groups $(4.5 ; 5.5 ; 6.5)$ were not statistically significant (permutation $\mathrm{p}=$
0.1099 to 0.6076$)$.

\section{Discussion}

We investigated the $\mathrm{pH}$ reaction norm in two freshwater flagellates: Mallomonas striata and Synura echinulata. The reaction norm is defined as a set of phenotypes produced by a genotype over a range of environments. We examined the traits concerning silica scale shape over a range of $\mathrm{pH}$. The impact of $\mathrm{pH}$ on population growth was used to evaluate optimal/suboptimal conditions. In M. striata a $\mathrm{pH}$ of 4.5 , and in S. echinulata $\mathrm{pHs}$ of 3.5 and 7.5 were considered suboptimal. The $\mathrm{pH}$ tolerance observed under laboratory conditions differed slightly from the results of field studies. Mallomonas striata represents an alkaliphilic to $\mathrm{pH}$ indifferent species, absent only in extremely acidic conditions (SIVER 1995). It was previously found in localities ranging from 5.2 to $9.0 \mathrm{pH}$ (weighted mean $\mathrm{pH} 7.8$ ). In our experiments, $M$. striata tolerated the $\mathrm{pH}$ of $4.5,5.5,6.5,7.5,8.3$ and 8.7 well. Surprisingly, a growing population was obtained at $\mathrm{pH}$ of 4.5 (Fig. 7). This indicates that even though $M$. striata is able to survive under low $\mathrm{pH}$ conditions, in combination with other factors (e.g. resource competition) in natural localities it may result in population densities so low that they are undetectable. Synura echinulata was described as an acidophilic taxon that easily tolerates habitats with low $\mathrm{pH}$ and alkalinity (weighted mean pH 5.9; SIVER 1995). Of the taxa found at low $\mathrm{pH}, \mathrm{S}$. echinulata has been reported over the largest $\mathrm{pH}$ range. It has been observed, although rarely, above pH 8 (KRISTIANSEN 1985; 
NĚMCová et al. 2003). Synura echinulata grew well at $3.5,4.5,5.5,6.5$ and $7.5 \mathrm{pH}$, with the optimum at $\mathrm{pH} 6.5$ (Fig. 8), which is consistent with the data from large populations found in nature.

The relationship between $\mathrm{pH}$ and size of scales was not clearly ascertained by this study (data not shown). The scale size in Mallomonas and Synura was found to be significantly affected by the cultivation temperature in previous studies. The size of scales decreased constantly with increasing temperature within a natural range of conditions (̌̌EZÁČOVÁ-ŠKALOUdOVÁ et al. 2010; PichrTová \& NĚMCOVÁ 2011) in accordance with the "temperature rule" (AtKInson et al. 2003). While the "temperature rule" indicating reduction in cell size with increasing temperature, was verified in a wide range of aquatic protists, data on the $\mathrm{pH}-$ cell size relationship is still limited. A wide range of responses have been observed under controlled experimental conditions, as well as in natural populations (Воотн 2001; NeUSTUPA \& Hodač 2005; Weisse \& Stadler 2006; Černá \& Neustupa 2010).

However, we conclude there was a significant effect of $\mathrm{pH}$ on the scale shape in both investigated species, although the proportion of the shape variance explained by regression models differed $(27.6 \%$ in Mallomonas striata and $8.0 \%$ in Synura echinulata). The relationship between shape and $\mathrm{pH}$ remained significant, and even when we controlled for the size effect on scale shape a considerable portion of the shape variance was still explained by regression analysis (19.1\% in M. striata and $7.1 \%$ in S. echinulata). The shape determined for Mallomonas striata var. serrata (CCMP 2059) scales across the tested $\mathrm{pH}$ gradient was congruent with the model based on the GM landmark method proposed by NEUSTUPA \& NĚMCOVÁ (2007) for this variety. In that study Mallomonas striata var. serrata scale shape reconstruction was based on 25 images of scales collected worldwide. Mallomonas striata var. serrata differed from the type variety in having wide and short anterior flanges, narrower shield and thicker V-rib (Neustupa \& NĚMCOVÁ 2007). As we investigated the scale shape plasticity of M. striata var. serrata over a wide $\mathrm{pH}$ range we concluded that the appearance of anterior flanges was the most stable character, and it is not subject to change. The anterior flanges were always short and wide, while the area of the shield and the thickness of the V-rib differed with respect to $\mathrm{pH}$ (Fig. 11). Scale shape variation of Synura echinulata in crossed gradients of light and temperature was studied by NĚMCOVÁ et al. (2010). Interestingly, scales produced in low illumination combined with low temperature exhibited very similar shape patterns to those from the high $\mathrm{pH}$ treatment in this study. In both studies, these treatments represented suboptimal conditions, where scales were characterized by an extended shield area and a considerably reduced labyrinthic pattern. Nevertheless, we think it is still premature to consider this shape pattern to emerge as a consequence of suboptimal conditions.

The ordination pattern of the canonical analysis of Mallomonas striata scale shape showed a strong differentiation between low and neutral vs. high $\mathrm{pH}$ treatments (Fig. 9); however, in Synura echinulata extreme $\mathrm{pH}$ treatments were distinct from the others (Fig. 10). While clouds of scores spanned by the first two canonical axes in S. echinulata were clearly segregated (with the exception of $\mathrm{pH} 4.5$ and 6.5 groups), a certain degree of overlap was observed among groups of low and neutral treatments, and among groups of high $\mathrm{pH}$ treatment in M. striata. Nevertheless, all the investigated groups of scales were significantly different in shape in both $M$. striata and S. echinulata.

As a consequence of a symmetrisation procedure, where an asymmetric part of variation was eliminated, the mean value on disparity (the extent of scale shape plasticity) was almost three times lower in Synura echinulata compared to Mallomonas striata. Under the suboptimal conditions, characterized by low growth, the extent of scale plasticity in S. echinulata tended to increase. Conversely, this could not be said to apply to $M$. striata, where slightly increased plasticity at $\mathrm{pH} 4.5$ was observed, congruent with slower growth. Nevertheless, the greatest scale shape plasticity was revealed at higher $\mathrm{pH}$ treatments, where growth of populations was optimal. Increased phenotypic plasticity has been correlated to environmental stress (Kristensen et al. 2003; Neustupa et al. 2008), generally characterized by reduced growth. We propose that increased scale shape plasticity of synurales in environments approaching $\mathrm{pH} 9$ is not associated with stress, but to a decreased availability of dissolved reactive silicon. Silicon in the form of the weak monosilicic acid $\left(\mathrm{H}_{4} \mathrm{SiO}_{4}\right)$ is exploitable by chrysophytes in environments below pH $\sim 9$ (Reynolds 2006). Moreover, M. striata cells from higher $\mathrm{pH}$ 
treatments unmistakably economized on the silicon, thus producing significantly thinner scales with considerably reduced $\mathrm{V}$-rib hoods (Fig. 11; pH 8.3 and 8.7). Investigation of the correlation between scale-shape patterns that develop under high $\mathrm{pH}$ with those of scales produced in $\mathrm{Si}$-impoverished medium with an optimal $\mathrm{pH}$, would help to clarify the cause(s) of scale shape variability. Increased scale shape variation associated with either $\mathrm{pH}$ stress or reduced $\mathrm{H}_{4} \mathrm{SiO}_{4}$ availability may decrease the ability of cells to compose a perfectly fitting, functional scale case. Imperfectly armoured cells may become more susceptible to infections, parasites and predators. The protective role of "armor" in the development and turnover of algal populations was emphasised by HAMM \& SMETACEK (2007). Besides the inability of synurophytes to use bicarbonate as a source of inorganic carbon (Bhatti \& Colman 2008; Saxby-Rouen et al. 1997), increased scale shape plasticity may represent the other reason why these organisms avoid highly alkaline natural environments.

Finally, we asked, how may the size of scales influence their shape (the effect of allometry). Multivariate regression of shape on centroid size explained $2.3 \%$ and $6.2 \%$ of variance in Mallomonas striata and Synura echinulata, respectively. Among photosynthetic protists, shape changes associated with cell size were described in Micrasterias semicells (Neustupa et al. $2008 ; 37.5 \%$ of shape variation was explained by size), cenobial cells of Pediastrum duplex (NEUSTUPA \& HODAČ 2005; size accounted for $13.9 \%$ of total shape variation) and in frustules of a pennate diatom Achnanthidium (PоTAPOVA \& HAMILTON 2007). In these organisms allometric effect was obviously associated with cellular growth. After the silica scales mature, silicify and are exocytosed to the cell surface their shape is fixed and invariable (LEADBEATER \& BARKER 1995), consequently the allometric effect is weaker (PichrTOVÁ \& NĚMCOVÁ 2011; this study). Size accounted for $5.3 \%$ and $12.2 \%$ of total scale shape variation in $S$. petersenii and M. tonsurata, respectively (PICHRTová \& NĚMCOVÁ 2011). Allometry in synurophyte scales is not related to growth of scales but may reflect their position within the scale case (NeUSTUPA et al. 2010).

Silica scales of both investigated species expressed distinctive phenotypes over a range of tested $\mathrm{pH}$, yet all of the observed shapes fitted within original descriptions of the taxa. Organisms are evolutionarily designed to survive under the multifactorial conditions of nature, and can respond to a large number of factors that surely differ from the conditions in a test tube (GIMMLER 2001). Additional data collected on silica scales of natural populations will further advance our understanding of the relationship between scale shape and key environmental factors, and may help us to evaluate the potential of scale shape in paleoecological reconstructions. Application of partial least-squares analysis within geometric morphometrics (RoHLF 2006) will enable us to visualize correlations of shape changes with a set of variables and to compare those shape patterns to the $\mathrm{pH}$ related shape plasticity revealed in this study.

\section{Acknowledgements}

The authors thank to Magda Škaloudová for technical assistance. This study was partly supported by grant No. 206/08/P281 of the Czech Science Foundation, and Research Grant No. 21620828 of the Czech Ministry of Education.

\section{References}

Atkinson, D.; Ciotti, B.J. \& Montagnes, D.J.S. (2003): Protists decrease in size linearly with temperature: ca. $2.5 \%{ }^{\circ} \mathrm{C}^{-1}$. - Proceedings of the Royal Society of London Series B-Biological Sciences 270: 2605-2611.

Baltanás, A.; Alcorlo, P.; Danielopol, D.L. (2002): Morphological disparity in populations with and without sexual reproduction: a case study in Eucypris virens (Crustacea: Ostracoda). Biological Journal of the Linnean Society 75 : 9-19.

Bhatti, S. \& Colman, B. (2008): Inorganic carbon acquisition in some synurophyte algae. Physiologia Plantarum 133: 33-40.

Bookstein, F.L. (1991): Morphometric tools for landmark data: geometry and biology. - 435 pp., Cambridge University Press, Cambridge.

Bоотн, R.K. (2001): Ecology of testate amoebae (Protozoa) in two lake superior coastal wetlands: Implications for paleoecology and environmental monitoring. - Wetlands 21: 564576.

BRÖnMARK, C. \& Hansson, L.A. (2005): The biology of lakes and ponds. - 285 pp., Oxford University Press, Oxford.

ČErná, K. \& Neustupa, J. (2010): The pH-related morphological variations of two acidophilic species of Desmidiales (Viridiplantae) isolated from a lowland peat bog, Czech Republic. - 
Aquatic Ecology 44: 409-419.

Debat, V.; Begin, M.; Legout, H. \& David, J.R. (2003): Allometric and nonallometric components of Drosophila wing shape respond differently to experimental temperature. - Evolution 57: 2773-2784.

Foote, M. 1993. Discordance and concordance between morphological and taxonomic diversity. Paleobiology 19: 185-204.

GaVrilova,O.V.; Nogina,N.V.\&VoloshKo,L.N.(2005): Scale structures and growth characteristics of Synura petersenii (Synurophyceae) under different $\mathrm{pH}$ conditions. - Nova Hedwigia. Beihefte 128: 249-256.

Gimmler, H. (2001): Acidophilic and acidotolerant algae. - In: RAI, L.C. \& GAUR, J.P. (eds): Algal adaptations to environmental stresses. - pp. 259-290, Springer-Verlag, Berlin, Heidelberg, New York.

Gondar, D.; Lopez, R.; Fiol, S.; Antelo, J.M. \& Arce, F. (2005): Characterization and acid-base properties of fulvic and humic acids isolated from two horizons of an ombrotrophic peat bog. - Geoderma 126: 367-374.

Grant, J.; Tekle, Y. I.; Andersen, O.R.; Patterson, D. J. \& KATZ, L.A. (2009): Multigene evidence for the placement of a heterotrophic amoeboid lineage Leukarachnion sp. among photosynthetic stramenopiles. - Protist 160: 376-38.

Gutowski,A.(1996): Temperature dependent variability of scales and bristles of Mallomonas tonsurata Teiling emend. Krieger (Synurophyceae). Nova Hedwigia. Beihefte 114: 125-146.

Hamm, C. \& SmetaceK, V. (2007): Armor: Why, when and how? In: Falkowski, P. \& Knoll, A. (eds): The evolution of aquatic photoautotrophs: $311-$ 332. Elsevier Academic Press.

Hammer, Ø.; Harper, D.A.T. \& Ryan, P.D. (2001): PAST: paleontological statistics software package for education and data analysis. Palaeontologia Electronica 4: 1-9.

Klingenberg, C.P.; Barluenga, M. \& Meyer, A. 2002. Shape analysis of symmetric structures: quantifying variation among individuals and asymmetry. - Evolution 56: 1909-1920.

Kristensen, T.N.; Pertoldi, C.; Andersen, D.H. \& LoeschCKe, V. (2003): The use of fluctuating asymmetry and phenotypic variability as indicators of developmental instability: a test of a new method employing clonal organisms and high temperature stress. - Evolutionary Ecology Research 5: 53-68.

KRISTIANSEN, J. (1985): Occurrence of scale-bearing Chrysophyceae in a eutrophic Danish lake. Internationale Vereinigung für theoretische und angewandte Limnologie. Verhandlungen 22: 2826-2829.

Leadbeater, B.C.S. \& Barker, D.A.N. (1995):
Biomineralization and scale production in the Chrysophyta. - In: SAndgren, C.D.; Smol, J.P. \& Kristiansen, J. (eds): Chrysophyte algae: ecology, phylogeny, and development. - pp. 141-164. Cambridge University Press, Cambridge.

LEE, K.L. \& KIM, H.S. (2007): Growth characteristics of three synurophytes (Mallomonas species) at different temperatures and $\mathrm{pH}$. - Nova Hedwigia 84: 227-240.

Martin-Wagenmann, B. \& Gutowski, A. (1995): Scale morphology and growth characteristics of clones of Synura petersenii (Synurophyceae) at different temperatures. - In: SANDGREN, C.D.; Smol, J.P. \& Kristiansen, J. (eds): Chrysophyte algae: ecology, phylogeny, and development. - pp. 345-360, Cambridge University Press, Cambridge.

NĚmcová, Y.; Neustupa, J.; Nováková, S. \& Kalina, T. (2003): Silica-scaled chrysophytes of the Czech Republic. - Acta Universitatis Carolinae Biologica 47: 285-346.

NĚmcovÁ, Y.; Neustupa, J.; KvíderovÁ, J. \& ŘEzÁčovÁŠKaloudovÁ, M. (2010): Morphological plasticity of silica scales of Synura echinulata (Synurophyceae) in crossed gradients of light and temperature - a geometric morphometric approach. - Nova Hedwigia. Beihefte 136: 21-32.

Neustupa, J.; ŘEzÁČovÁ-ŠKaloudovÁ, M. \& NĚMcovÁ, Y. (2010): Shape variation of the silica-scales of Mallomonas kalinae (Mallomonadales, Synurophyceae) in relation to their position on the cell body. - Nova Hedwigia. Beihefte 136: $33-42$.

Neustupa, J. \& Hodač, L. (2005): Changes in shape of the coenobial cells of an experimental strain of Pediastrum duplex var. duplex (Chlorophyta) reared at different pHs. - Preslia 77: 439-452.

Neustupa, J. \& NĚMcovÁ, Y. (2007): A geometric morphometric study of the variation in scales of Mallomonas striata (Synurophyceae, Heterokontophyta). - Phycologia 46: 123-130.

Neustupa, J.; ŠŤastný, J. \& Hodač, L. (2008): Temperature-related phenotypic plasticity in the green microalga Micrasterias rotata. Aquatic Microbial Ecology 51: 77-86.

Pichrtová, M. \& NĚmcová, Y. (2011): Effect of temperature on size and shape of silica scales in Synura petersenii and Mallomonas tonsurata (Stramenopiles). - Hydrobiologia 673: 1-11.

Potapova, M. \& Hamilton, P.B. (2007): Morphological and ecological variation within the Achnanthidium minutissimum (Bacillariophyceae) species complex. - Journal of Phycology 43: 561-575.

ReYNOLDS, C.S. (2006): Ecology of phytoplankton. - 552 pp., Cambridge University Press, 
Cambridge.

ŘEzÁČOvÁ-ŠKaloudovÁ, M.; Neustupa, J. \& NĚMcovÁ, Y.(2010): Effect of temperature on the variability of silicate structures in Mallomonas kalinae and Synura curtispina (Synurophyceae). - Nova Hedwigia. Beihefte 136: 55-70.

Rohlf, F.J. (2006): Tps series. Department of Ecology and Evolution, State University of New York at Stony Brook, New York.

Saxby-Rouen, K.J.; Leadbeater, B.S.C. \& Reynolds, C.S. (1997): The growth response of Synura petersenii (Synurophyceae) to photon flux density, temperature, and $\mathrm{pH}$. - Phycologia 36: 233-243.

Siver, P.A. (1991): The biology of Mallomonas. Morphology, taxonomy, ecology.

Developments in Hydrobiology 63: 1-228.

SivER, P.A. (1995): The distribution of chrysophytes along environmental gradients: their use as biological indicators. - In: SANDGREN, C.D.; Smol, J.P. \& Kristiansen, J. (eds): Chrysophyte algae: ecology, phylogeny, and development. - pp. 232-268. Cambridge University Press, Cambridge.

Siver, P.A. (1999): Morphological observations of Synurophycean algae from some acidic habitats, including the description of a sub-specific taxon. - Nordic Journal of Botany 19: 121-127.

Siver, P.A. \& Wolfe, A.P. (2005): Scaled chrysophytes in Middle Eocene lake sediments from Northwestern Canada, including descriptions of six new species. - Nova Hedwigia. Beihefte 128: 295-308.

Wee, J.L.; Millie, D.F. \& Walton, S.P. (1991): A statistical characterization of growth among clones of Synura petersenii (Synurophyceae). - Journal of Phycology 27: 570-575.

Weisse, T. \& Stadler, P. (2006): Effect of pH on growth, cell volume, and production of freshwater ciliates, and implications for their distribution. - Limnology and Oceanography 51: 1708-1715.

Zeeb, B.A. \& Smol, J.P. (2001): Chrysophyte scales and cysts. - In: SMOL, J.P.; BirKS, H.J.B. \&. LAST, W.M (eds): Tracking environmental change using lake sediments. Vol. 3 Terrestrial, algal, and siliceous indicators. - pp. 203-223, Kluwer Academic Publishers, Dordrecht.

Zelditch, M.L.; Swiderski, D.L.; Sheets, D.H. \& FINK, W.L. (2004): Geometric morphometrics for biologists: a primer. - 443 pp., Elsevier Academic Press, London.

(C) Czech Phycological Society (2012)

Received November 28, 2011

Accepted February 12, 2012 